\title{
WestVirginiaUniversity.
}

Department of Economics

Working Paper Series

\section{The Effect of Superstar Players on \\ Game Attendance: Evidence from the NBA}

Brad R. Humphreys

Candon Johnson

Working Paper No. 17-16

This paper can be found at the College of Business and Economics Working Paper Series homepage: 


\title{
The Effect of Superstar Players on Game Attendance: Evidence
}

\section{from the NBA}

\author{
Brad R. Humphreys* \\ Candon Johnson ${ }^{\dagger}$ \\ West Virginia University \\ West Virginia University
}

July 31, 2017

\begin{abstract}
Economic models predict that "superstar" players generate externalities that increase attendance and other revenue sources beyond their individual contributions to team success. We investigate the effect of superstar players on individual game attendance at National Basketball Association games from 1981/82 through 2013/14. Regression models control for censoring due to sellouts, quality of teams, unobservable team/season heterogeneity, and expected game outcomes. The results show higher home and away attendance associated with superstar players. Michael Jordan generated the largest superstar attendance externality, generating an additional $5,021 / 5,631$ fans at home/away games.
\end{abstract}

Keywords: superstar effect, attendance demand, censored normal estimator JEL Codes: Z2,L83

\section{Introduction}

A substantial literature in economics examines the presence of superstar effects in specific markets. Superstar effects refer to the presence of specific individuals or organizations earning far more than others and dominating activities. Superstar effects can exist in a number of settings, including corporate CEOs, graduate schools, researchers, classical and popular music performers, movie stars, textbook markets, and sports. The presence of superstar effects can explain observed differences in the distribution of earnings across individuals. The theoretical basis for superstar effects was

\footnotetext{
${ }^{*}$ West Virginia University, College of Business \& Economics, 1601 University Ave., PO Box 6025, Morgantown, WV 26506-6025, USA; Email: brhumphreys@mail.wvu.edu.

${ }^{\dagger}$ West Virginia University, College of Business \& Economics, 1601 University Ave., PO Box 6025, Morgantown, WV 26506-6025, USA; Email: cjohns77@mix.wvu.edu
} 
established under general conditions by Rosen (1981) and extended by Adler (1985) and MacDonald (1988).

These competing models, and the specific predictions made by these models, generated a substantial body of empirical research, much of it based on outcomes in professional sports markets. Hausman and Leonard (1997), Lucifora and Simmons (2003), Franck and Nüesch (2012), Jane (2016) and Lewis and Yoon (2016) develop evidence supporting the presence of superstar effects on attendance, salaries, broadcast audiences, and revenues in a number of professional sports leagues.

We extend this literature by examining the effect of the presence of superstar players on attendance at National Basketball Association (NBA) games over the 1981-82 through 2013-14 regular seasons. Our sample of game-level attendance and game characteristics data is substantially longer than any used in previous research which permits a number of interesting extensions to the existing literature. We augment these data with detailed information about the talent and popularity of specific NBA players. This allows us to test for superstar effects in a comprehensive approach that

includes a number of different players from different eras in the NBA. We find strong evidence of superstar effects associated with specific NBA players at home games and road games throughout the sample period.

Our data also permit a formal test of the Rosen (1981) model of superstar effects, which posits talent as the primary source of superstar effects versus the Adler (1985) model of superstar effects, which posits popularity as its source. Franck and Nüesch (2012) undertook a similar test using data from German football. We find evidence of specialization of superstar effects; Larry Bird appears to be a "Rosen" superstar, deriving superstar status from talent while Michael Jordan and LeBron James, appear to be "Adler" superstars deriving superstar status from popularity. These results indicate that the findings of Franck and Nüesch (2012) can be generalized to other settings.

\section{Superstars, Talent and Popularity}

Interest in the economics of superstars stems from the classic paper by Rosen (1981), who developed a model explaining why relatively small groups of people in a given occupation earn enormous salaries and dominate their occupations, which he described as the "superstar" effect. Rosen developed a model containing profit maximizing firms and utility maximizing consumers describing 
how the number of tickets sold by a service producing firm like a sports team or concert venue depends on both ticket prices and the talent or quality of the performers. In this model, revenues are convex in talent; high-talent performers attract audiences much larger than performers with only slightly less talent and the marginal returns to talent exceed the underlying difference in talent across performers. The model predicts that a small number of athletes with marginally more talent or ability than their peers will have far more fans who will pay to watch them play and earn much larger salaries than their peers.

Adler (1985) extended this line of research to show that substantial differences in the number of fans following specific performers, and the revenues generated by these large numbers of fans, could arise even if there is no discernable difference in talent or ability between performers. This model emphasizes the idea that following a star performer requires the acquisition of knowledge about performers, which is costly, and the presence of spillover benefits associated with this knowledge in the form of enhanced social interaction with others, since many people share common knowledge about star performers. Under these conditions, fans will flock to performers with star power even of the underlying level of talent is identical. The implication is that popularity, not differences in skill, explain observed star effects. Adler (1985) also assumes that luck plays a large role in determining which specific performers successfully attract a sufficiently large fan base to be considered a star.

MacDonald (1988) generalized the model developed by Rosen (1981) to a dynamic setting including "young" and "old" performers to explore why some performers become stars and others do not. The model includes good and bad performances and heterogeneity in consumer preferences for (appreciation of) high quality performances. The model makes predictions about entry by performers, the number of fans of young and old performers, and ticket prices, but still emphasizes the key feature in Rosen (1981): differences in skill, not differences in popularity, explain the presence of star performers.

These models of star power and consumer behavior generated a large, growing body of empirical research examining the effect of star players on television audiences and attendance at NBA games. The NBA is an ideal setting for analyzing the impact of superstar players on consumer demand. NBA teams can only put five players on the floor at a time compared to the NFL (11 players on the field at one time and two full sets of players, offense and defense), MLB and MLS (9), or NHL (6) so the impact of individual players on fan interest is larger in the NBA. Unlike football and 
hockey players, NBA players do not wear protective headgear and padding that distorts players' faces and body shape. Unlike the NFL and MLB, NBA games are played in smaller venues where many fans sit close to the playing surface.

Hausman and Leonard (1997) performed the first empirical analysis of the effect of superstar players on television audiences and attendance in the NBA. Hausman and Leonard (1997) analyzed local and national television broadcast audience size data and attendance data from the 1989-1990 and 1991-1992 seasons and found that superstar players are valuable to not only the team that employs them, but also other teams. They found that superstars, identified by the top 25 allstar vote recipients, increased attendance, television ratings, licensed merchandise sales, and other sources of revenues beyond their individual contributions, including increased attendance at road games. Hausman and Leonard (1997) also analyzed the impact of five individual superstar players, Magic Johnson, Larry Bird, Shaquille O’Neil, Charles Barkley and Michael Jordan (then in the prime of his career with the Chicago Bulls) on home and away attendance and revenues. They estimated that Michael Jordan was worth more than $\$ 50$ million to other teams in the NBA, which they identified as a superstar externality since Jordan was paid only by the Chicago Bulls.

Berri and Schmidt (2006) extended the work of Hausman and Leonard (1997), analyzing attendance at away games played by NBA teams. The impact of star players on attendance at away games is interesting because superstar players are compensated by their team, not their opponents; increased attendance and gate revenues at away games primarily benefits opposing teams, so this represents a superstar player externality. Berri and Schmidt (2006) analyze total season attendance at NBA road games over the 1992-1993 through 1995-1996 seasons and define the presence of star players on NBA teams based on the total number of all-star votes received by players on each team. Each additional all-star vote was associated with an increase of 0.005 in total season attendance at road games. For top vote getters in all-star voting in the 1995-1996 NBA season like Grant Hill (1.36 million votes) or Michael Jordan (1.34 million votes), this implies an increase in annual attendance of about 7,000 additional tickets sold, or about $\$ 220,000$ in additional revenues assuming an average NBA ticket price of $\$ 30$. Berri and Schmidt (2006) also estimated the additional revenues generated by additional wins generated by star players holding the all-star effect constant and reported estimate of the marginal revenues from an additional wins to be substantially larger than the marginal revenue from additional all-star votes. 
Jane (2016) analyzed the effect of star players on NBA game attendance rather than total season attendance using a number of measures of the presence of star players on teams. Variables reflecting star players include 30 highest paid players in the league, the top 30 players in the league in five specific performance statistics, the number of all-star players appearing in each game for each team, and the number of all-star votes received by players on each team. (Jane, 2016) found that stars, measured as all-star vote recipients and the leagues' top performers, have a positive impact on game attendance. In differentiating between popular players that received all-star votes and top performers, Jane (2016) found that popularity, not performance, affects attendance.

Empirical research on the effect of stars on attendance extends to other sports. Lucifora and Simmons (2003) and Franck and Nüesch (2012) analyze the distribution of player compensation in European football leagues to assess the extent to which this distribution reflects the presence of star players. Lucifora and Simmons (2003) report evidence supporting superstar effects in salaries earned by football players in Italy. Franck and Nüesch (2012) report evidence supporting superstar effects in independently generated estimates of the value of football players in Germany.

Lewis and Yoon (2016) analyze both the distribution of salaries and individual game attendance at Major League Baseball (MLB) games to assess the impact of star baseball players. They report evidence that the number of star players on home and visiting MLB teams increases attendance at games, controlling for other factors, as well as evidence that star players have a larger impact on attendance on teams playing in larger cities. Lewis and Yoon (2016) also estimate that the presence of star player Manny Ramirez on the Los Angeles Dodgers' roster in 2008 generated an additional 4,815 tickets sold, and that this increase in attendance can be attributed to star power, not improvements in the Dodgers' on-field performance.

Franck and Nüesch (2012) Empirically tested the determinants of superstar status. Franck and Nüesch (2012) observe that the superstar model developed by Rosen (1981) identifies talent as the source of superstar effects but the model developed by Adler (1985) predicts that popularity could generate superstar effects among players with identical talent. Franck and Nüesch (2012) devise a clever test of talent versus popularity using quantitative measures of media coverage of German football players as a proxy for popularity and on-pitch success in rank order tournaments as a measure of talent. They find evidence that both factors explain superstar effects in this setting.

A number of key issues emerge from the existing literature on superstar effects. First, the unit 
of observation for attendance matters. Tests using individual game attendance provide sharper estimates of the superstar externality than aggregated data. Second, measuring superstar qualities requires some care. Superstar effects can stem from talent or popularity, so empirical models need to contain measures of both to avoid confusing superstar effects with other factors driving variation in attendance. All-star game votes and the presence of all-star players on team rosters represent common proxies for popularity. A wide variety of player-specific performance measures have been proposed and used as proxies for talent. Third, identifying superstar players requires some subjective judgements, and both general measures of the presence of superstars on teams, and player-specific superstar characteristics appear to explain variation in attendance. Fourth, mixed evidence on the relative importance of talent and popularity exists in the literature. Resolving this issue requires more data, and different measures of popularity and talent.

\section{Empirical Analysis}

\section{Data Description}

The data represent the most comprehensive NBA game-specific attendance and outcome data available. The data set contains information on more than 36,500 NBA regular season games played over the 1981-82 through 2013-14 seasons, including game attendance and point spreads for nearly all games played. Most attendance research using game-level NBA attendance data analyze outcomes from a few seasons (Jane, 2016). Attendance data are missing from 60 games, most of which were in the $1987-88$ season. $^{1}$

Game attendance data were collected to augment the game outcome data used by Price et al. (2010) and Soebbing and Humphreys (2013). Most of the game-level NBA attendance data come from box scores found on basketball-reference.com. However, these box scores are missing attendance data for some games, including a large number of games in the 1988-89 season. We filled in these missing observations by consulting microfiche archives of past print editions of The New York Times and The Washington Post.

Table 1 contains summary statistics for key continuous variables in the data. NBA games

\footnotetext{
${ }^{1}$ Details on the construction of this data set can be found in Price et al. (2010) and Soebbing and Humphreys (2013). These papers use a subset of this data set.
} 
Table 1: Summary Statistics - Continuous Variables

\begin{tabular}{lrrrr}
\hline & Mean & Std Dev & Min & Max \\
\hline Game Attendance & 15944 & 4183 & 1335 & 62046 \\
Home team's record prior to game & 0.498 & 0.186 & 0 & 1 \\
Away team's record prior to game & 0.503 & 0.187 & 0 & 1 \\
Closing Spread for the home Team & -3.739 & 6.292 & -25 & 49 \\
Metro Area Population & 49.72 & 47.43 & 7 & 201 \\
Number of All-star vote recipients on home team & 1.698 & 1.398 & 0 & 6 \\
Number of All-star vote recipients on away team & 1.694 & 1.400 & 0 & 6 \\
Number of All-star votes received by home team & 90 & 104 & 0 & 725 \\
Number of All-star votes received by away team & 90 & 105 & 0 & 725 \\
\hline Observations & 36712 & & & \\
\hline
\end{tabular}

occasionally take place in football stadiums like the Georgia Dome in Atlanta, which generates a few games with exceptionally large attendance. Also, a few teams in the sample played home games in domed football stadiums. This includes the Detroit Pistons, who played home games in the Pontiac Silverdome from 1978 through 1988 (capacity more than 80,000), the Seattle SuperSonics, who played home games in the Kingdome in Seattle through the 1984-1985 season (basketball capacity 60,000), and the San Antonio Spurs, who played home games in the Alamodome between 1993 and 2002 (basketball capacity 39,500). The maximum value for game attendance on Table 1 is a March 1998 game between the Atlanta Hawks and the Detroit Pistons played in the Georgia Dome, an enclosed football stadium seating 71,000 .

The team winning percentage variables reflect the fraction of past games won by each team prior to the current game. This variable reflects team quality at that point in the season. The average value of theses variables is less than 0.500 because of the missing attendance data. The missing observations tend to be for games played by home teams with winning percentages above 0.500 .

The point spread variable shows the number of points by which the home team is expected to win each game. A negative value means the home team is favored to win. The average home team in the sample was expected to win by about 4 points, reflecting the well-known home advantage in sports.

We collected data on two team-level factors that reflect the number of "star" players on each team. Each season the NBA plays an "all star" game at roughly mid season. Each conference fields 


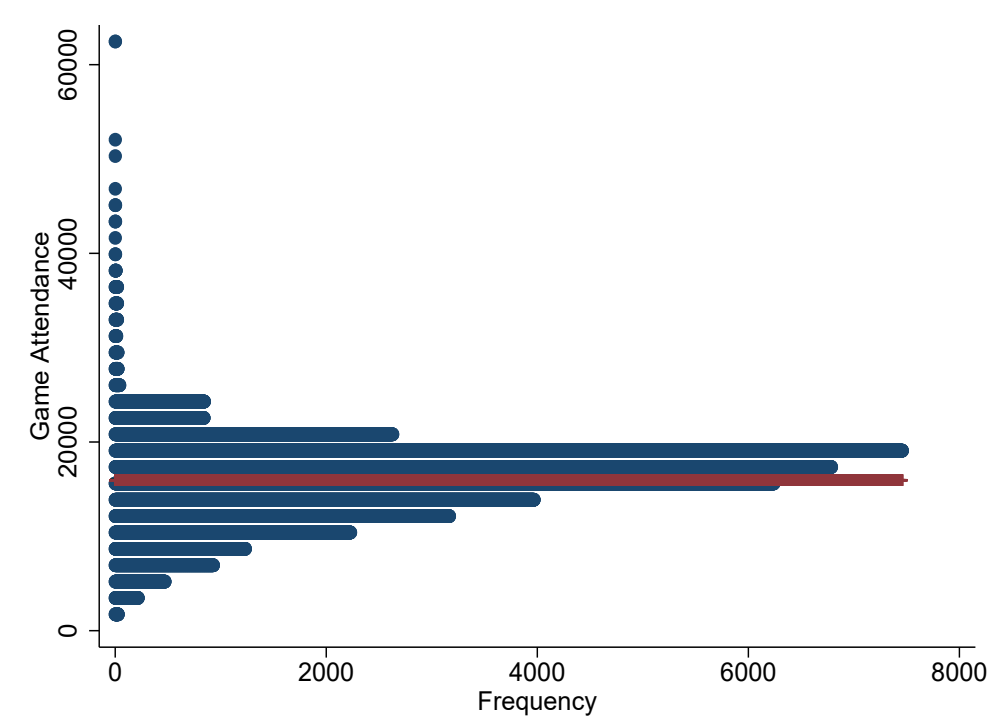

Figure 1: Game Attendance Distribution

a team in this game, and the participants in the game are determined by fan voting, so the number of votes received by each player reflects fan's opinions about the star status of each player. We collected data on the number of players on each team that received votes from fans. On average each team in the sample had about 1.6 players who received votes. We also collected data on the total number of votes received by players on each team, which is a second measure of fan opinions about the "star power" of players on each team.

The key outcome variable is game attendance. Figure 1 shows the distribution of game attendance in the sample. The distribution is fairly symmetric at attendance below about 25,000 and has a distinct tail of games with large attendance. This tale includes one-off games in football stadiums and some home games played by teams playing in large facilities like the Pistons, SuperSonics, and Spurs.

Table 2 summarizes the dichotomous variables in the data. We do not report standard deviations for these variables. The first set identify games played by the previous season's champion and games played on weekends (defined as Friday, Saturday and Sunday). A disproportionate number of NBA games are played on weekends, which make up only $3 / 7$ of possible game days.

The key variables on Table 2 identify games played by a select group of star players from the sample period: Larry Bird (Boston Celtics 1979-1992), Earvin "Magic" Johnson (Los Angeles Lak- 
ers 1979-1991, 1996), Michael Jordan (Chicago Bulls 1984-1993, 1995-1998; Washington Wizards 2001-2003), Tim Duncan (San Antonio Spurs 1997-2016), and LeBron James (Cleveland Cavaliers 2003-2009, Miami Heat 2010 - 2014). Note the sample ends with the 2013-2014 season, so LeBron James' return to Cleveland did not occur in this sample. Note that Magic Johnson retired in 1991 and briefly returned to the Lakers in 1996, playing in 32 games.

Variables identifying games in which Larry Bird, Earvin "Magic" Johnson, Michael Jordan, Tim Duncan, and LeBron James played were constructed using information from game logs during their careers through the 2013-2014 NBA season. These game logs were matched with the game attendance data for each contest. To account for games missed in which each player was a gametime decision or sat out for rest, in other words instances where players missed a single game, were included in the indicator variable for player appearances. These games are included because when a player appearance in a game is a game-time decision, fans will reasonably expect them to play in the game and their behavior will not be effected. When a player rests, it is commonly not announced until moments before the game begins.

Long periods of missed games due to injury are omitted from the player appearance indicator variables. Most of these cases involve extended periods where the player was injured. For example, Michael Jordan appeared in only 18 games in the 1985-86 season, his second season in the NBA. He played in the first three games of the season, broke a bone in his hand, and did not rejoin the team until 15 March. We code the period between 29 October 1985 and 15 March 1986 as Jordan not playing. A similar approach is used for other player injuries in the sample.

For these star players, data were collected to determine the extent to which they are "popular" and also the extent to which they perform exceptionally on the court. To measure popularity, the number of All-Star votes were collected for each individual player in each season. To account for performance, data on each player's Value over Replacement Player (VORP) and Win Shares are collected for each player. Both are advanced performance statistics.

VORP compares the impact of players to a theoretical replacement player based on their Box Score Plus/Minus (BPM) and the actual percentage of their team's minutes played. Box Score Plus/Minus estimates how well a player performs compared to the average player per 100 possessions, which is defined as 0.0. For example, in 2008-2009 LeBron James posted a record 12.99 BPM, which means James was 12.99 points better per 100 possessions than the average player in 
the league. For the purposes of VORP, -2 is considered the value of a replacement player. The formula for $\operatorname{VORP}$ is $[\mathrm{BPM}(-2.0)]^{*}($ percentage of minutes played)*(team games/82). NBA performance analysts generally consider VORP the best measure of a players' contribution to team performance.

Win Shares measure how many wins in a season can be directly attributed to the performance of a specific player. It gives an individual player credit for their contribution to team wins. If a team wins 65 games, 65 win shares will be divided between the individual players on the team.

Table 2: Summary Statistics - Dichotomous Variables

\begin{tabular}{lc}
\hline & Mean \\
\hline Home team is the defending champions & 0.036 \\
Away team is the defending champions & 0.036 \\
Weekend & 0.470 \\
Game played in the United Center & 0.021 \\
Game played in the American Airlines Arena & 0.014 \\
Game played in the AT\&T Center & 0.013 \\
Game played in the Verizon Center & 0.018 \\
Larry Bird plays for the Home team & 0.010 \\
Larry Bird plays for the Away team & 0.010 \\
Magic Johnson plays for the Home team & 0.011 \\
Magic Johnson plays for the Away team & 0.011 \\
Michael Jordan plays for the Home team & 0.014 \\
Michael Jordan plays for the Away team & 0.015 \\
Tim Duncan plays for the Home team & 0.017 \\
Tim Duncan plays for the Away team & 0.018 \\
LeBron James plays for the Home team & 0.012 \\
LeBron James plays for the Away team & 0.012 \\
\hline Observations & 36712 \\
\hline
\end{tabular}

Table 2 summarizes the dichotomous variables capturing player appearance in games, previousseason team success, and game characteristics in the sample. About 3.6\% of the games in the sample included the previous season's championship team. These games may have higher attendance if fans prefer to see recent championship teams play. Almost half the games in the sample took place on Friday, Saturday or Sunday. The NBA prefers to schedule games on weekends if possible. Relatively few of the games in the sample had one of the five superstar players appear in the game. We exploit this variation to assess the impact of the presence of superstar players on attendance. 


\section{Identifying Superstars}

Superstar status is not randomly assigned to NBA players and we lack an instrument that would permit econometric identification of superstar status. Given these limitations, identifying specific superstar players requires some subjective decisions. We relied on the following criteria when identifying NBA superstars. To be considered a superstar, a player needed to be highly touted upon entering the league, be widely considered one of the league's premiere talents, exhibit extended excellence on the court throughout his career, and not regress to a point that they were no longer a centerpiece of their team late in their career.

The players best fitting this criteria were Michael Jordan, Magic Johnson, Larry Bird, Tim Duncan, and LeBron James. Each was a high draft pick in the entry draft and performed at a high level immediately. Duncan, Bird, Jordan, and Johnson each made the All-Star Game in their rookie seasons. Duncan, Bird, James, and Jordan all received the NBA Rookie of the Year award. These players did not experience a drastic decline in performance that many players experience late in their career, but continued to appear in All-Star games and produce at a high level until retirement. Note that Duncan and James played past the 2013-2014 season, the end of our sample, and Johnson retired relatively early due to health issues.

Table 3 summarizes the career performance of the five NBA players identified as superstars for this analysis. All five were among the first players taken in the entry draft, had long careers, and played in the All-Star game in almost every season during their careers. They also collected large numbers of All-star votes, indicating that these players enjoyed widespread popularity among fans. Each played on teams that won multiple championships, and each won multiple league Most Valuable Player (MVP) awards. The career average VORP and Win Share numbers are the average value of these advanced performance metrics across each season played. In all cases, these players directly accounted for more than 10 wins per season for their teams. These VORP and Win Share averages indicate sustained performance at exceptional levels throughout their careers.

Note that other stars players were considered, but ultimately not included on this list. These players include Charles Barkely, Shaquille O'Neal, Kareem Abdul-Jabbar, and Kobe Bryant. Each of these players was an exceptional talent and likely attracted fans to games, but didn't fit the criteria as well as those selected. Both Barkley and Bryant took longer to reach star status in 
Table 3: Superstar Credentials

\begin{tabular}{lrrrrrrrr}
\hline & $\begin{array}{r}\text { Seasons } \\
\text { Played }\end{array}$ & $\begin{array}{r}\text { Draft } \\
\text { Pos. }\end{array}$ & $\begin{array}{r}\text { All-star } \\
\text { Games }\end{array}$ & $\begin{array}{r}\text { All-star Votes } \\
\text { per Season }\end{array}$ & $\begin{array}{r}\text { Champ. } \\
\text { Won }\end{array}$ & $\begin{array}{r}\text { MVP } \\
\text { Awards }\end{array}$ & $\begin{array}{r}\text { Average VORP } \\
\text { per Season }\end{array}$ & $\begin{array}{r}\text { Average Win Shares } \\
\text { per Season }\end{array}$ \\
\hline Larry Bird & 13 & 6 & 12 & 500,354 & 3 & 3 & 6.12 & 11.22 \\
Magic Johnson & 13 & 1 & 11 & 577,633 & 5 & 3 & 5.95 & 11.98 \\
Michael Jordan & 15 & 3 & 14 & 995,460 & 6 & 5 & 6.97 & 14.26 \\
LeBron James & 11 & 1 & 10 & $1,924,418$ & 2 & 4 & 8.65 & 15.34 \\
Tim Duncan & 17 & 1 & 14 & $1,099,762$ & 5 & 2 & 4.87 & 11.26 \\
\hline
\end{tabular}

the NBA, and each struggled late in their careers with injury. Barkley did not make the All-Star team until his third season in the league and Bryant appeared in only one All-Star game over his first three seasons in the league. Shaquille O'Neal was a strong candidate because he came into the league and produced immediately, but late in his career injuries happened frequently and he changed teams often, playing for four different teams in his final five seasons. Kareem Abdul-Jabbar is excluded because the data set only contains the second half of his 14 season career, which began in the 1969-70 season.

\section{Empirical Methods}

We follow the general approach in the literature and estimate reduced form empirical models explaining observed variation in attendance at NBA games; Berri and Schmidt (2006), Jane (2016), and Lewis and Yoon (2016) all use this approach. The general form of this empirical model is

$$
A_{i j s t}=f\left(T_{i j s t}, G_{i j s t}, S T A R_{i j s t}, e_{i j s t}\right)
$$

where $A_{i j s t}$ is total game attendance at a game played between home team $i$ and visiting team $j$ on date $t$ in NBA season $s . T_{i j s t}$ is a vector of variables capturing the characteristics of the two teams involved in each game, including variables reflecting team quality and venue. $G_{i j s t}$ is a vector of variables reflecting the characteristics of each individual game, including factors like the day of the week the game was played on, characteristics of the arena the game is played in, and local population. $S T A R_{i j s t}$ is a vector of variables reflecting the presence of star players on team $i$ and team $j$.

$e_{i j s t}$ is a random variable reflecting all other factors that affect attendance at individual NBA games. $e_{i j s t}$ is assumed to be a mean zero random variable with possibly heteroscedastic variance 
that may be correlated across observations for individual teams. Equation (1) can be interpreted as an approximation to the optimality conditions that emerge from a general economic model of attendance at sporting events that includes profit maximizing teams and utility maximizing customers/fans.

Estimating the unobservable parameters of Equation (1) presents a number of econometric problems. Foremost is censoring of the dependent variable. $A_{i j s t}$ is limited by the capacity of the arena that the home team plays in. NBA games are popular, and a number of games in the sample are "sell outs" where every available ticket to the game was sold. In these cases, consumer interest in the game exceeds the capacity of the arena, potentially biasing parameter estimates from Equation (1). For example, right-censoring of the dependent variable could lead to downward bias in the parameter capturing the effect of the presence of star players on team rosters on game attendance.

The standard econometric approach to correct for censoring of dependent variable is to use a limited dependent variable estimator like the Tobit estimator. Jane (2016) transforms the dependent variable to the percent of capacity based on reported arena capacity, a variable right-censored at 100, and uses the Tobit estimator. Lewis and Yoon (2016) do not control for censoring; sellouts at MLB games are much less common than sellouts at NBA games. Our sample contains numerous censored observations for the dependent variable. Based on the reported capacity of NBA arenas, about 10,000 of the 36,000 games in this sample were sellouts.

We correct for censoring of the dependent variable using a censored normal estimator (Amemiya, 1973). The censored normal estimator is a maximum likelihood estimator. Amemiya (1973) proved the consistency and asymptotic efficiency of this estimator under fairly general conditions. The primary advantage of the censored normal estimator relative to the Tobit estimator is that the censored normal estimator allows for the censored value to vary across observations while the Tobit estimator requires all observations of the dependent variable to be censored at the same value.

We also cluster correct the estimated standard errors at the home team market level. Within a season, local economic conditions, including population, may not vary enough to affect attendance. Explanatory variables reflecting team composition like the number of players receiving all-star votes on a team do not vary within season. However, the dependent variable, game attendance, varies throughout the season. This game to game variation reduces the estimated standard errors on 
variables that do not vary within season, requiring a cluster correction. We also use the standard White-Huber "sandwich" correction for heteroscedasticity.

\section{Empirical Results}

We estimate three alternative empirical models, corresponding to three different measures of star players on each team found in the literature. The results generated by estimating these models using the censored normal estimator with cluster corrected robust standard errors are shown on Table 4. Model (1) contains a variable reflecting the total number of all star votes received by players on the home and visiting team in each game. Model (2) contains variables reflecting the total number of players on the home and visiting team in each game that received all star votes in that season. Model (3) contains indicator variables for the presence of specific star players on the rosters of home and visiting teams in each game. Models (1) and (2) reflect general popularity from star players on teams, since all star votes reflect only fan popularity. Model (3) reflects performancebased star player effects and popularity. Table 4 reports parameter estimates and robust estimated standard errors. All models also contain home and visiting team-specific fixed effects and seasonspecific fixed effects. Using the censored normal estimator allows for an assessment of the effect of changing explanatory variables on attendance that is not limited by the capacity of the arena.

The variables capturing factors other than star player effects reported on Table 4 are generally statistically different from zero and have the expected signs. Attendance varies with both home team and visiting team quality, as measured by each team's winning percentage at that point in the season. Home team quality has a bigger impact on attendance than visiting team quality. The defending league champion draws larger crowds at home and on the road.

The results show that fans prefer to see games that the home team is expected to win. Betting market data proxies for fan expectations of game outcomes. The point spread variable is negative when the home team is favored in a game; each additional one point decrease in the point spread reflects a better expected performance by the home team relative to the visiting team. The parameter estimate on the point spread variable is negative and significant, suggesting that more fans attend games the home team is expected to perform better in. Weekend games draw more fans than week night games. The parameter estimate on the MSA population variable is not statistically different from zero. After controlling of other factors like team quality and fan expectation, as well 
Table 4: Regression Results - Censored Normal Regression Estimator

\begin{tabular}{|c|c|c|c|}
\hline & (1) & $(2)$ & $(3)$ \\
\hline Home team record before game & $\begin{array}{c}4918^{* * *} \\
7.47\end{array}$ & $\begin{array}{c}5182^{* * *} \\
9.01\end{array}$ & $\begin{array}{c}6004^{* * *} \\
9.96\end{array}$ \\
\hline Away team record before game & $\begin{array}{c}3046^{* * *} \\
7.87\end{array}$ & $\begin{array}{c}3235^{* * *} \\
9.41\end{array}$ & $\begin{array}{c}3864^{* * *} \\
10.69\end{array}$ \\
\hline Home team defending champions & $\begin{array}{c}2456^{* * *} \\
4.74\end{array}$ & $\begin{array}{c}2615^{* * *} \\
5.82\end{array}$ & $\begin{array}{c}2189^{* * *} \\
5.49\end{array}$ \\
\hline Away team defending champions & $\begin{array}{c}776^{* * *} \\
4.34\end{array}$ & $\begin{array}{c}1032^{* * *} \\
5.73\end{array}$ & $\begin{array}{c}942^{* * *} \\
5.84\end{array}$ \\
\hline Closing Point Spread & $\begin{array}{l}-49.9^{*} \\
-2.42\end{array}$ & $\begin{array}{c}-42.91^{*} \\
-2.32\end{array}$ & $\begin{array}{c}-54.86^{* *} \\
-3.09\end{array}$ \\
\hline Weekend games & $\begin{array}{c}1599^{* * *} \\
10.13\end{array}$ & $\begin{array}{c}1588^{* * *} \\
10.31\end{array}$ & $\begin{array}{c}1586^{* * *} \\
10.11\end{array}$ \\
\hline Metro Area Population & $\begin{array}{c}16.85 \\
0.84\end{array}$ & $\begin{array}{c}13.75 \\
0.68\end{array}$ & $\begin{array}{c}24.24 \\
1.06\end{array}$ \\
\hline Number of All-star votes received by Home team & $\begin{array}{c}8.903^{* * *} \\
3.30\end{array}$ & - & - \\
\hline Number of All-star votes received by Away team & $\begin{array}{c}6.782^{\text {*** }} \\
10.92\end{array}$ & - & - \\
\hline Number of All-star vote recipients on Home team & - & $\begin{array}{c}541^{* * *} \\
4.38\end{array}$ & - \\
\hline Number of All-star vote recipients on Away team & - & $\begin{array}{c}348^{* * *} \\
11.54\end{array}$ & - \\
\hline Game played in the United Center & - & - & $\begin{array}{c}6335^{* * *} \\
7.74\end{array}$ \\
\hline Game played in the American Airlines Arena & - & - & $\begin{array}{c}1642^{* *} \\
2.65\end{array}$ \\
\hline Game played in the AT\&T Center & - & - & $\begin{array}{l}-158 \\
-0.46\end{array}$ \\
\hline Game played in the Verizon Center & - & - & $\begin{array}{c}3035^{* * *} \\
5.19\end{array}$ \\
\hline Bird home games & - & - & $\begin{array}{c}5561^{* * *} \\
10.44\end{array}$ \\
\hline Bird road games & - & - & $\begin{array}{c}4289^{* * *} \\
11.68\end{array}$ \\
\hline Magic home games & - & - & $\begin{array}{c}1826^{* * *} \\
3.48\end{array}$ \\
\hline Magic road games & - & - & $\begin{array}{c}820 \\
1.27\end{array}$ \\
\hline Jordan home games & - & - & $\begin{array}{c}4983^{* * *} \\
3.99\end{array}$ \\
\hline Jordan road games & - & - & $\begin{array}{c}5751^{* * *} \\
11.36\end{array}$ \\
\hline Duncan home games & - & - & $\begin{array}{c}2560^{* * *} \\
4.17\end{array}$ \\
\hline Duncan away games & - & - & $\begin{array}{c}-234.8 \\
-1.26\end{array}$ \\
\hline LeBron home games & - & - & $\begin{array}{c}5521^{\text {*** }} \\
9.11\end{array}$ \\
\hline LeBron away games & - & - & $\begin{array}{c}3255^{* * *} \\
8.37\end{array}$ \\
\hline $\begin{array}{l}\text { Observations } \\
\text { Psuedo- } R^{2}\end{array}$ & $\begin{array}{c}36,712 \\
0.050\end{array}$ & $\begin{array}{c}36,712 \\
0.051\end{array}$ & $\begin{array}{c}36,712 \\
0.053\end{array}$ \\
\hline
\end{tabular}


as season-specific unobservable heterogeneity, the size of the local market in terms of population does not explain game-to-game variation in attendance.

The parameter estimates capturing the effect of general fan popularity, in terms of star players, on attendance are positive and significant in Models (1) and (2). Attendance at NBA games increases as total star player popularity for the home team and visiting team increases (Model 1) and as the number of popular star players on each team increases (Model 2). This is consistent with results reported in Jane (2016) using a smaller sample of NBA games.

We also estimate models containing indicator variables for specific star players appearing in games. The empirical literature on star effects in the NBA contains numerous example of estimates of specific star players on attendance and television audiences. Hausman and Leonard (1997) estimate the impact of Larry Bird and Michael Jordan. Berri et al. (2004) estimate the impact of Michael Jordan, Shaquille O'Neal, Charles Barkley and Grant Hill. Jane (2016) estimates the impact of 20 specific players. All three of these papers use data from a limited number of seasons. Our data set permits a comprehensive assessment of the impact of specific star players on NBA game attendance, allows for an assessment of the effect of star players separately from the effect of team popularity.

Note that three of these players played for teams that opened new arenas while they were on the team or shortly before the players joined these teams. The new venues are the United Center which opened in Chicago in 1994 while Michael Jordan played for the Bulls, the Verizon Center which opened in Washington DC in 1995, a few seasons before Jordan joined the Wizards, the AT\&T Center which opened in San Antonio in 2002 while Tim Duncan was playing for the Spurs, and the American Airlines Arena which opened in Miami in 2000 several seasons before LeBron James joined the Heat. New facilities increase attendance as sporting events, a phenomena known as the "novelty effect" (Coates and Humphreys, 2005). To control for novelty effects of these venues on attendance, we include an indicator for games played in these arenas in the regression model containing individual player indicator variables. From Column (3) on Table 4, positive novelty effects are present in all arenas except the AT\&T Center.

Figure 2 shows the parameter estimates and $95 \%$ confidence intervals for the five super star players identified above: Magic Johnson, Larry Bird, Michael Jordan, Tim Duncan and LeBron James. The careers of these five players span the entire sample period and all clearly fall into 


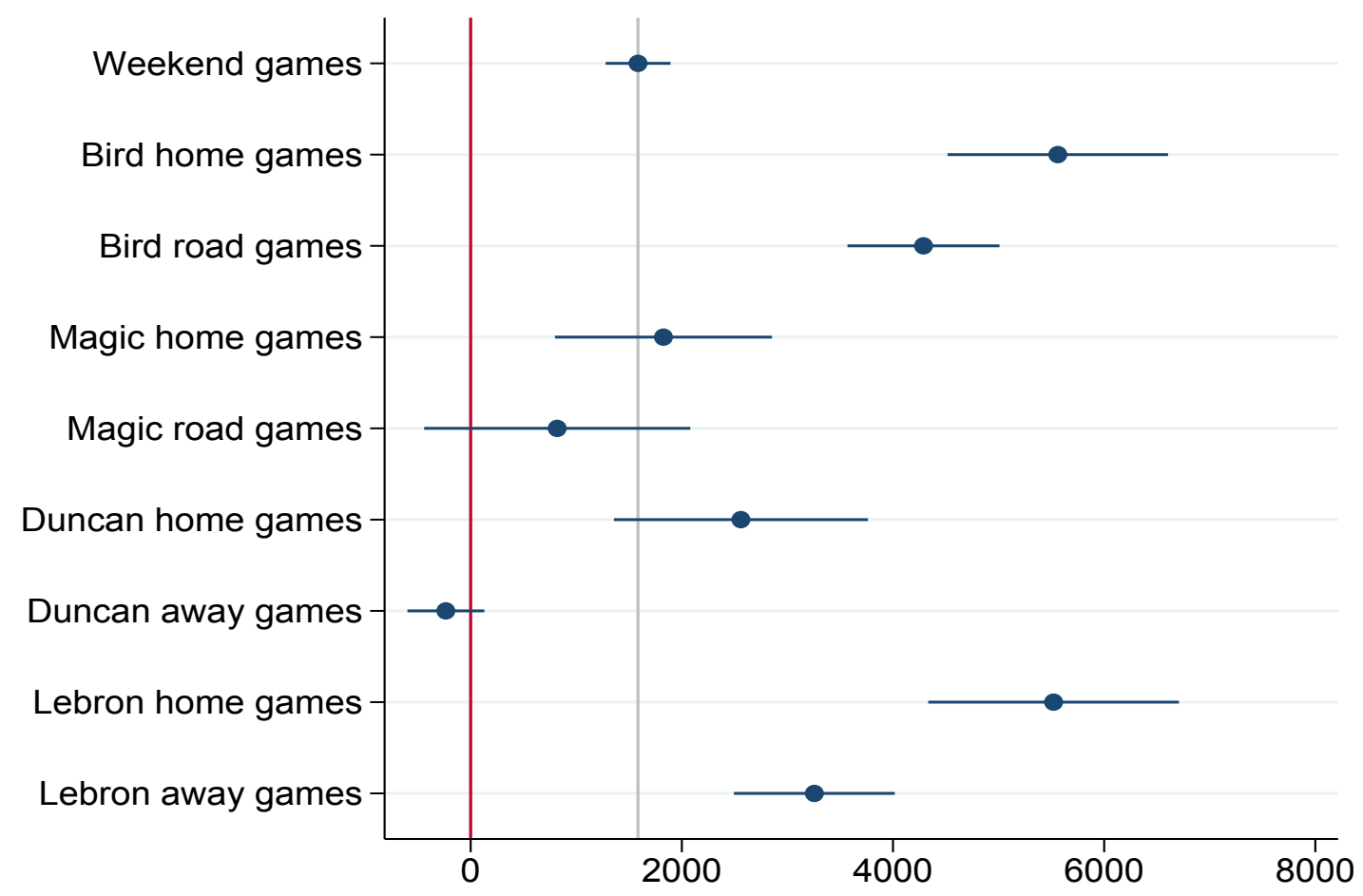

Figure 2: Superstar Effects on Game Attendance - Specific Players

the category of super stars. Both Jordan and James changed teams in our sample period. Unfortunately, we cannot estimate a separate effect for LeBron James while playing for the Cleveland Cavaliers and Miami Heat or Michael Jordan while playing for the Chicago Bulls and Washington Wizards. The Heat sold out all 155 home games they played while LeBron James was on their roster over the 2010-11 to 2013-14 seasons, so no separate LeBron effect on Heat attendance can be estimated using a censored regression approach; the same was true for Michael Jordan's stint with the Wizards. Instead, we estimate an overall LeBron effect on both Miami Heat and Cleveland Cavalier attendance and an overall Jordan effect on both the Bulls and Wizards.

Figure 2 also contains the point estimate for the weekend indicator variable from Model (3) on Table 4. This parameter estimate, which represents the conditional effect of moving an NBA game from a weeknight to Friday, Saturday, or Sunday holding all other factors constant, is precisely estimated and provides an objective and intuitive test for assessing the superstar power of specific athletes. If the impact of a specific player's presence in a game is less than the impact of moving that game from Wednesday night to Saturday, then that player may not qualify as a superstar. 
Based on this criteria, the sample contains three superstar NBA players over the sample period: Larry Bird, Michael Jordan and LeBron James. While the other players analyzed generate a statistically significant number of additional fans at home NBA games, these players did not generate more additional home fans than moving their games from a weeknight to a weekend, other things equal. The also did not generate additional attendance at away games.

\section{Testing Talent Versus Popularity}

Franck and Nüesch (2012) and Jane (2016) perform tests assessing the importance of player talent and popularity for explaining superstar externalities. Franck and Nüesch (2012) analyze estimates of individual player market values. Jane (2016) uses team-level measures of total player talent and popularity to generate estimates of the effect of additional player talent and popularity, then uses these estimates to assess the value of additional attendance attributable to specific players. Given the large panel of game specific attendance and information about games in which specific players appeared, we can empirically test for the relationship between player-specific measures of talent and popularity on game attendance, formally testing for differences in the predictions of the Rosen (1981) superstar model versus the predictions of the Adler (1985) model.

Again, the Rosen (1981) superstar model predicts that small differences in player talent generates large differences in attendance, broadcast audiences, and player earnings while the Adler (1985) model predicts that players with identical talent could still generate substantial additional attendance, broadcast audiences, and player earnings because of differences in player popularity in the presence of knowledge-based information spill overs from following specific players. We use the total number of All-star votes received each season by specific players as a measure of popularity. NBA fans can vote for specific players to appear in the annual All-star game. While fan votes may depend on many factors including team effects and perceptions of player performance, the persistent appearance of some players on the All-star team roster suggest that All-star votes reflect player popularity. Jane (2016) interprets All-star votes as a measure of player popularity. We use VORP, which depends only on player performance measures, as a proxy for player talent.

The empirical approach estimates Equation (1) replacing the indicator variable for a specific player appearing in a game with that player's VORP and total All-star game votes in the current season. This provides separate measures of a player's average talent and level of popularity in each 
season. We include three superstar players identified above in this regression model: Larry Bird, Michael Jordan and LeBron James. The lack of any statistically significant increase in road game attendance in games played by Tim Duncan and Magic Johnson on Table 4 suggests they were not in the same class as these three players.

Table 5: Regression Results - Player Talent versus Popularity Dependent Variable: Game Attendance

\begin{tabular}{lrr}
\hline & \multicolumn{2}{c}{ Explanatory Variable } \\
Player & Season VORP & All-star Votes \\
\hline Larry Bird & $451^{* * *}$ & 2.357 \\
& $(3.33)$ & $(1.65)$ \\
Michael Jordan & -48.37 & $5.469^{* * *}$ \\
& $(-0.52)$ & $(4.36)$ \\
LeBron James & 192 & $1.093^{*}$ \\
& $(1.70)$ & $(2.04)$ \\
\hline Observations & 36,712 & 36,712 \\
$R^{2}$ & 0.06 & 0.06 \\
\hline
\end{tabular}

t-stats in parentheses. ${ }^{*}$ : significant at $5 \% ;{ }^{* *}: 1 \%$; **: $0.1 \%$.

Table 5 summarizes the results of this regression analysis. Table 5 reports only the parameter estimates and t-statistics for the player-specific popularity and talent variables. All other parameter estimates are qualitatively identical to the results on Table 4 and are not reported.

Table 5 contains an interesting pattern. One of these superstar players, only Larry Bird appears to generate a superstar externality based on talent. Bird's total season VORP, a proxy for player talent, is associated with statistically significant increases in game attendance but his All-star vote totals are not associated with additional attendance at games. The other two superstars, Michael Jordan and LeBron James, appear to generate superstar externalities based on their popularity. Jordan and James' All-star vote totals, a measure of popularity, are associated with statistically significant increases in game attendance, holding talent constant, but their total season VORP is not associated with additional game attendance. Franck and Nüesch (2012) and Jane (2016) find evidence that both popularity and talent generate superstar effects, but neither finds evidence of specialization in superstar effects. Bird is a "Rosen" superstar, while Jordan and James are "Adler" superstars. 


\section{Conclusions}

Models of superstar effects predict large differences in individual earnings when differences in individual abilities are small or non-existent. Documenting the presence of superstar effects in actual economic outcomes is important, because the presence of superstar effects can explain differences in income inequality. The presence of superstar effects also has important implications for policies governing player compensation and league-wide revenue distribution in professional sports leagues, a setting where the teams that pay players' salaries may not be able to capture the increased revenues generated by superstar players in road games.

This paper develops new evidence documenting the presence of superstar effects in the NBA. While other papers found similar results, the data here cover a large number of NBA games played over more than 30 seasons, which permits a comprehensive empirical analysis. We find evidence of large superstar effects over the entire 30 year period, establishing that superstar effects persist throughout different eras. Michael Jordan and LeBron James retained their superstar status when moving from team to team, indicating portability of the superstar effect. The robust nature of the superstar effect in the NBA implies that superstar effects may be widespread throughout the economy, and perhaps represents a larger explanation for observed income inequality than previously thought.

The data also permit a detailed analysis of the determinants of superstar status. We find evidence supporting both the Rosen (1981) superstar model and the Adler (1985) superstar model, although these two explanations apply to different superstar players in the sample. The results indicate that both models explain superstar effects. Again, this suggests that superstar effects may be more common in the economy than previously thought, since both talent and popularity can independently explain superstar status. 


\section{References}

Adler, M. (1985). Stardom and talent. The American Economic Review, 75(1):208-212.

Amemiya, T. (1973). Regression analysis when the dependent variable is truncated normal. Econometrica, 41(6):997-1016.

Berri, D. J. and Schmidt, M. B. (2006). On the road with the National Basketball Association's superstar externality. Journal of Sports Economics, 7(4):347-358.

Berri, D. J., Schmidt, M. B., and Brook, S. L. (2004). Stars at the gate the impact of star power on NBA gate revenues. Journal of Sports Economics, 5(1):33-50.

Coates, D. and Humphreys, B. R. (2005). Novelty effects of new facilities on attendance at professional sporting events. Contemporary Economic Policy, 23(3):436-455.

Franck, E. and Nüesch, S. (2012). Talent and/or popularity: what does it take to be a superstar? Economic Inquiry, 50(1):202-216.

Hausman, J. A. and Leonard, G. K. (1997). Superstars in the National Basketball Association: Economic value and policy. Journal of Labor Economics, 15(4):586-624.

Jane, W.-J. (2016). The effect of star quality on attendance demand: The case of the National Basketball Association. Journal of Sports Economics, 17(4):396-417.

Lewis, M. and Yoon, Y. (2016). An empirical examination of the development and impact of star power in Major League Baseball. Journal of Sports Economics, pages 1-33.

Lucifora, C. and Simmons, R. (2003). Superstar effects in sport: Evidence from Italian soccer. Journal of Sports Economics, 4(1):35-55.

MacDonald, G. M. (1988). The economics of rising stars. The American Economic Review, $78(1): 155-166$.

Price, J., Soebbing, B. P., Berri, D., and Humphreys, B. R. (2010). Tournament incentives, league policy, and NBA team performance revisited. Journal of Sports Economics, 11(2):117-135.

Rosen, S. (1981). The economics of superstars. The American Economic Review, 71(5):845-858. 
Soebbing, B. P. and Humphreys, B. R. (2013). Do gamblers think that teams tank? evidence from the NBA. Contemporary Economic Policy, 31(2):301-313. 